\title{
Neurointensive Care for Spinal Injuries; Perspective on Its Role in Early Stage
}

\author{
Woo-Keun Kwon ${ }^{1,3}$, Dong-Hyuk Park ${ }^{2}$, Jong-Keon $\mathrm{Oh}^{3,4}$, Jang Hun Kim ${ }^{5}$, Haewon Roh ${ }^{1,3}$, Hong Joo Moon ${ }^{1}$, \\ Joo Han Kim ${ }^{1}$, Youn-Kwan Park ${ }^{1}$
}

${ }^{1}$ Department of Neurosurgery, Korea University Guro Hospital, Korea University College of Medicine, Seoul, Korea

${ }^{2}$ Department of Neurosurgery, Korea University Medical Center, Anam Hospital, Korea University College of Medicine, Seoul, Korea

${ }^{3}$ Focused Training Center for Trauma, Korea University Guro Hospital, Korea University College of Medicine, Seoul, Korea

${ }^{4}$ Department of Orthopedic Surgery, Korea University Guro Hospital, Korea University College of Medicine, Seoul, Korea

${ }^{5}$ Department of Neurosurgery, Korean Armed Forces Capital Hospital, Seongnam, Korea

Received: March 26, 2019

Accepted: April 1,2019

Corresponding Author:

Woo-Keun Kwon M.D., Ph.D.

Department of Neurosurgery,

Korea University Guro Hospital,

Korea University College of

Medicine, 148 Gurodongro,

Gurogu, Seoul 08308, Korea

Tel : 82-2626-3100

Fax : 82-863-1684

E-mail: kwontym@gmail.com
Multimodal approach to the patient is essential in neurocritical care for spinal cord injury (SCI) patients. This article highlights the issues regarding early stage neurointensive care for SCI. Although there are still some debate regarding the optimal neurointensive care in SCI patients, it is clear by previous literature that proper medical and surgical management play important role for neurocritical care in SCI patients. Not only neurologica problems but also several life threatening medical issues such as DVT, PE, respiration problems or pressure sores should also be considered during the early neurointensive care in order to optimize treatment for SCI patients. By understanding the early role of neurointensive care in $\mathrm{SCI}$, we believe we can better treat these patients.

Keywords: Spinal cord injury; Neurointensive care; Spine

\section{INTRODUCTION}

Spinal cord injury (SCI) is a devastating state following high energy trauma, which results in devastating burden to the patient and to the society as well, and the prevalence is known to be more than 700 per million ${ }^{5)}$. As SCIs mostly lead to irreversible sequalae and neurologic deficits, it finally results in great social costs as well as heart-aching personal loss. The functional impairment and the socioeconomic burden induced by SCI is already well documented ${ }^{1,11}$. On the papyrus from ancient Egypt 4000 years ago, the Egyptians state SCI as "The disease that cannot be cured" ${ }^{\prime 9)}$. In the modern era, SCI is not considered as a disease that cannot be cured, but it is true that it is still a disease that is difficult to deal with for both the clinicians and the patients themselves. Although many studies have been taken to the field regarding the treatment for spinal cord injury, many of SCI patients still finally remain with remnant neurologic deficits. Considering the impact of this injury on each patients, and also considering its socioeconomic burden, proper approach to the SCI patients and good selection of treatment modalities are of great interest. Especially, the early stage of treatment is of importance. During last several decades, there have been dramatic development and evolutionary improvement in the treatment for SCI with or without spinal vertebral injuries. Not to mention the great progression on acute care and neurointensive care in the early stage of SCI. In this article, the focus is on the role of neuro-

Copyright (C) 2019 The Korean Neurointensive Care Society

This is an Open Access article distributed under the terms of the Creative Commons Attribution Non-Commercial License (http://creativecommons.org/licenses/by-nc/4.0/) which permits unrestricted non-commercial use, distribution, and reproduction in any medium, provided the original work is properly cited. 
critical care for SCI patients with a emphasis on its role in early stage of the patient evaluation.

\section{NEUROINTENSIVE CARE AT THE EMERGENCY ROOM}

Thorough inspection as well as further evaluation is essential for multiple trauma patients in the emergency room (ER) setting is mandatory, especially more when the patient has accompanied mental deterioration or neck injuries. These patients are at great risk for further neurologic deterioration because they are vulnerable to secondary injuries to the neural structures due to increased risk of muscle spasm, aggravating pain or uncontrolled instability of injured structures. Proper evaluation and management for the airway, breathing and circulation $(A B C)$ is essential as they are the hallmark of vital stability, and afterwards neurological examinations are undertaken. The physician should palpate the whole spectrum of spinal bony structures, trying not to induce any further secondary injuries, and the alignment of the spinal column might be checked here at the same time. Throughout this physical examination process, the patient should be considered as he or she has instability and maximal carefulness should be taken.

If the patient has accompanied severe traumatic brain injury (TBI) of Glasgow Coma Scale (GCS) 8 or less, the patient should be promptly intubated to secure the airway, and this is the same in case of suspected high cervical spine injuries. Spinal cord injuries at the level of $\mathrm{C5}$ or above are at great risk of alteration of respiratory function and are vulnerable to risk of dyspnea, fatigue of breathing muscles or even pulmonary functions ${ }^{12,13,17)}$. Therefore, tracheal intubation should be promptly considered in case of suspicious high cervical injuries. And when performing endotracheal intubation, minimizing the motion of cervical spine is important to avoid any further injuries to the unstable segment ${ }^{7 \text { ) }}$.

The next step would be detailed neurologic examination. As emphasized in the previous paragraphs, proper evaluation of the $\mathrm{ABC}$ and the presence of TBI should be done prior to the neurologic exam. Thorough examination evaluating the function of the central and peripheral nervous system should be done, and in cases of SCI, the American Spinal Injury Association (ASIA) scale is frequently used as a classification tool. According to the SCI patients' neurological status, proper selection for the next imaging study can be done. Under ER setting, anterior-posterior (AP) and lateral (LAT) plain radiograph images of the cervical, thoracic and lumbosacral area are taken as well as the open mouth view of high cervical spine. It is important to include the whole spine in evaluation. $10-15 \%$ of multiple trauma patients have non-contiguous spinal injuries 15), and therefore the whole spine must all be taken into initial evaluation. During evaluation of the spinal alignments, the cervico-thoracic junction (CTJ) can be difficult as they are easily hidden by the shoulder on $\mathrm{X}$ ray. Therefore, oblique images or swimmer's view images could be helpful for proper evaluation of the CTJ in trauma patients. Computer tomography (CT) including reconstruction of axial, sagittal and coronal images are greatly useful in evaluating the patient in the ER, and as the medical circumstances developed most trauma centers have immediate access to CT scans and they are considered as one of the mandatory initial evaluation tools. Magnetic resonance images (MRIs) are useful evaluating the injuries of soft tissue, intervertebral discs, ligaments and of course neural structures. Although the access to MRI is much limited compared to plain radiographs and CT scans, the role of MRI in early evaluation of SCI is greatly growing.

\section{OPTIMAL TIMING FOR EARLY NEUROINTENSIVE CARE IN SCI}

SCI after high energy impact to the spinal cord is a result of a primary spinal cord trauma followed by a subsequent secondary injury. Understanding this injury mechanism of SCI is a important step to understand SCI, and it also provides a basis for SCI management for both medical and surgical treatment modalities. Primary injury of the spinal cord is a change that occurs due to the direct insult to the spine. It is usually accompanied with breakage of the normal bony and ligamentous structural integrity of the spine, which results in compressive injury to the spinal cord. Consequently, neuronal axons, blood vessels and cell structures of the spinal cord gets injured ${ }^{12,17}$. By this primary step the vicious cascade of SCI is started and secondary injuries start to happen as well. Shortly after the primary injury, a focal intramedullary hemorrhage occurs as well as edematous change12), and this is the start of secondary injury. Then the micro blood circulation of the spinal cord gets affected by these changes, and formation of thrombus happens in conjunction with vasospasm, finally leading to a vicious cycle of spinal cord necrosis ${ }^{13)}$. The primary and secondary injury after SCI affects the final outcome of SCI patients whom undergo neurocritical care after trauma.

Then when is the optimal timing for neurointensive treatment of SCI. Although most studies recommend early initiation of neurointensive care, there is still no widely accepted global guidelines regarding the treatment of SCI or neuroregeneration after these injuries ${ }^{8,14)}$. However, in general, the goal of early initiation of medical neurointensive care is minimizing secondary injury of $\mathrm{SCI}$. And proper early decompression is suggested as the treat- 
ment of choice in cases of neural compressive injuries to optimize the neurointensive care for SCI. Many medical trials including the use of methylprednisolone, tirilazard mesylate, naloxone, nimodipine, other calcium channel blockers or GM1 gangliosides have been introduced but none of them have been brought to the clinical field as a standard treatment yet ${ }^{4,12,17)}$. Optimal timing of surgical decompression is under debate yet as well ${ }^{4,5,10)}$. But the general consensus is that when the SCI patient has marked instability as well as compressive injury of the spinal cord, early decompression within 24 hours might benefit the patient in terms of favorable outcome after neurointensive care for SCI.

\section{ADDITIONAL CONSIDERATIONS FOR EARLY NEUROINTENSIVE CARE IN SCI}

Medical and surgical neurointensive care for SCI are not the only points physicians should take care of. There are several important medical points that we should give emphasis to when dealing with SCI patients in the early phase. Deep vein thrombosis (DVT) and pulmonary embolism (PE) are important complications that SCI patients easily experience in the early neurointensive care period ${ }^{3)}$. Acute SCI patients have significantly higher risk of developing DVT or PE, and if proper preventions treatments are not done the risk gets up to $47-100 \%$ of these patients ${ }^{6)}$. PE itself is a devastating complication which can lead to mortality during neurointensive care for SCI. In order to avoid any possible risk of DVT or PE, injection of low molecular weight heparin (LMWH) is recommended as a preventive modality. In case of complete neurologic injury after SCI 40mg of LMWH or a twice injection of $30 \mathrm{mgs}$ a day are recommended. Use of mechanical compression devices also helps reducing the risk of DVT or PE during neurointensive care. Some trauma centers use inferior vena cava (IVC) filters empirically, but there are not enough evidence for its routine use ${ }^{6}$.

Pulmonary complications are the most common problems that occur during early neurointensive care for $\mathrm{SCI}^{3)}$. The phrenic nerve which innervates the diaphragm originates from the C3-5 nerves, so more proximal injury to the spinal cord can result as impairment of breathing. Although there are great variability case by case, and it is extremely unpredictable, a large portion of high cervical spine injury patients cannot get rid of ventilation support even after the acute phase of neurointensive care ${ }^{16)}$. Proper and intensive pulmonary care including the mechanical ventilation support, and also proper frequent suction of endotracheal materials are mandatory for these patients. As pneumonia are also very easily accompanied to these group of patients, extensive chest physiotherapy as well as proper selection of antibi- otics are important as well.

Furthermore, pressure sore of SCI patients should be considered as an important part even from the very early phase of neurointensive care. If proper care has not been taken for the SCI patient, up to $45 \%$ are known to develop pressure sores during their neurointensive care ${ }^{2)}$. In order to avoid this problem, position change every 2 hours are recommended, with especially more caring for prominent sites that are fragile to pressure sores. Good nutrition during this early period is important not only for the nutrition itself but it also prevents the development of pressure sores $^{2)}$.

\section{SUMMARY}

SCI usually results in devastating clinical outcomes, and proper neurocritical care is essential while managing these patients. Although there are still some debate regarding the optimal neurointensive care for SCI patients, it is clear by previous literature that proper medical and surgery care has a benefit for SCI patients in the early phase. Not only neurologica problems but also several life threatening medical issues such as DVT, PE, respiration problems or pressure sores should also be considered during the early neurointensive care in order to optimize treatment for SCI patients.

\section{CONFLICT OF INTEREST}

No potential conflict of interest relevant to this article was reported.

\section{REFERENCES}

1. Ackery A, Tator C, Krassioukov A. A global perspective on spinal cord injury epidemiology. J Neurotrauma 2004;21:13551370.

2. Bergstrom N, Braden B. A prospective study of pressure sore risk among institutionalized elderly. J Am Geriatr Soc 1992;40:747-758.

3. DeVivo MJ, Krause JS, Lammertse DP. Recent trends in mortality and causes of death among persons with spinal cord injury. Arch Phys Med Rehabil 1999;80:1411-1419.

4. Fehlings MG, Rabin D, Sears W, Cadotte DW, Aarabi B. Current practice in the timing of surgical intervention in spinal cord injury. Spine 2010;35:S166-173.

5. Fehlings MG, Vaccaro A, Wilson JR, Singh A, D WC, Harrop JS, et al. Early versus delayed decompression for traumatic cervical spinal cord injury: results of the surgical timing in acute 
spinal cord injury study (STASCIS). PloS One 2012; 7:e32037.

6. Geerts WH, Pineo GF, Heit JA, Bergqvist D, Lassen MR, Colwell CW, et al. Prevention of venous thromboembolism: the Seventh ACCP Conference on Antithrombotic and Thrombolytic Therapy. Chest 2004;126:338S-400S.

7. Gerling MC, Davis DP, Hamilton RS, Morris GF, Vilke GM, Garfin SR, et al. Effects of cervical spine immobilization technique and laryngoscope blade selection on an unstable cervical spine in a cadaver model of intubation. Ann Emerg Med 2000;36:293-300.

8. Hadley MN, Walters BC, Grabb PA, Oyesiku NM, Przybylski GJ, Resnick DK, et al. Guidelines for the management of acute cervical spine and spinal cord injuries. Clin Neurosurg 2002;49:407-498.

9. Lifshutz J, Colohan A. A brief history of therapy for traumatic spinal cord injury. Neurosurgical Focus 2004;16:E5.

10. Liu JM, Long XH, Zhou Y, Peng HW, Liu ZL, Huang SH. Is Urgent Decompression superior to delayed surgery for traumatic spinal cord injury? a meta-analysis. World Neurosurg 2016;87:124-131.

11. Rath N, Balain B. Spinal cord injury-The role of surgical treat- ment for neurological improvement. J Clin Orthop Trauma 2017;8:99-102.

12. Rowland JW, Hawryluk GW, Kwon B, Fehlings MG. Current status of acute spinal cord injury pathophysiology and emerging therapies: promise on the horizon. Neurosurgical Focus 2008;25:E2

13. Tator $\mathrm{CH}$, Fehlings MG. Review of the secondary injury theory of acute spinal cord trauma with emphasis on vascular mechanisms. J Neurosurg 1991;75:15-26.

14. Tator CH, Rowed DW, Schwartz ML, Gertzbein SD, Bharatwal $\mathrm{N}$, Barkin $\mathrm{M}$, et al. Management of acute spinal cord injuries. Can J Surg 1984;27:289-293; 296.

15. Vaccaro AR, An HS, Lin S, Sun S, Balderston RA, Cotler JM. Noncontiguous injuries of the spine. J Spinal Disord 1992;5:320-329.

16. Wicks AB, Menter RR. Long-term outlook in quadriplegic patients with initial ventilator dependency. Chest 1986;90:406410.

17. Witiw CD, Fehlings MG. Acute spinal cord injury. J Spinal Disord Tech 2015;28:202-210. 